in vivo $31: 267-283(2017)$

doi:10.21873/invivo.11056

Review

\title{
The Use of Proteomics in Assisted Reproduction
}

\author{
IOANNA KOSTERIA ${ }^{1}$, ATHANASIOS K. ANAGNOSTOPOULOS ${ }^{2}$, CHRISTINA KANAKA-GANTENBEIN ${ }^{1}$, \\ GEORGE P. CHROUSOS ${ }^{1,2}$ and GEORGE T. TSANGARIS ${ }^{2}$ \\ ${ }^{1}$ Division of Endocrinology, Diabetes and Metabolism, First Department of Pediatrics, \\ University of Athens, Aghia Sophia Children's Hospital, Athens, Greece; \\ ${ }^{2}$ Proteomics Research Unit, Biomedical Research Foundation of the Academy of Athens, Athens, Greece
}

\begin{abstract}
Despite the explosive increase in the use of Assisted Reproductive Technologies (ART) over the last 30 years, their success rates remain suboptimal. Proteomics is a rapidly-evolving technology-driven science that has already been widely applied in the exploration of human reproduction and fertility, providing useful insights into its physiology and leading to the identification of numerous proteins that may be potential biomarkers and/or treatment targets of a successful ART pregnancy. Here we present a brief overview of the techniques used in proteomic analyses and attempt a comprehensive presentation of recent data from mass spectrometry-based proteomic studies in humans, regarding all components of ARTs, including the male and female gamete, the derived zygote and embryo, the endometrium and, finally, the ART offspring both pre-and postnatally.
\end{abstract}

In developed countries, subfertility has become an increasing problem and, with time, increasing numbers of infertile couples are offered assisted reproductive technologies (ART) treatment to beget children. In general, ART-accomplished pregnancies account for 1-3\% of births in industrialized countries (1). ARTs are comprised mainly of classic in vitro

This article is freely accessible online.

Correspondence to: Dr. Athanasios K. Anagnostopoulos, Proteomics Research Unit, Biomedical Research Foundation of the Academy of Athens, 4 Soranou Ephessiou, 11527 Athens, Greece. Tel: +30 2106597383, Fax: +30 2106597498, e-mail: atanagnost@bioacademy.gr and Dr. George Th. Tsangaris, Proteomics Research Unit, Biomedical Research Foundation of the Academy of Athens, 4 Soranou Ephessiou, 11527 Athens, Greece. Tel: +30 2106597075, Fax: +30 2106597498, e-mail: gthtsangaris@bioacademy.gr.

Key Words: Proteomics, assisted reproduction, IVF, ICSI, fertility, sperm, oocyte, embryo, offspring health, epigenetics, review. fertilization (IVF), that first led to a living child in 1978 (2), and the Intracytoplasmic Sperm Injection (ICSI) procedure, that was introduced in 1992 , primarily to treat male subfertility (3).

However, despite the use of ART for more than 30 years and notwithstanding the increasing number of performed cycles, success rates are still suboptimal. According to the 2009 report by the European Society of Human Reproduction and Embryology, including data from 20072009 , pregnancy rates failed to show a year-to-year increase for the first time in 5 years (4). Not all ART attempts lead to successful pregnancies and an even smaller percentage results in successful deliveries. Indeed, successful pregnancy is achieved in $29,2 \%$ and $28,8 \%$ of IVF and ICSI aspirations, whereas delivery is accomplished in $22,4 \%$ and $21,1 \%$ of oocyte aspirations, respectively (5).

To date, gamete and embryo selection rely mainly on morphological criteria that have been highly debated, even though they were recently updated (6). In addition, hormonal hyperstimulation protocols, that include the use of chorionic gonadotropin (instead of luteinizing hormone) to induce multiple ovulation and leading to high progesterone levels are known to create a hostile endometrial environment (7-9). ART pregnancies have also been associated with increased rates of preterm labor, small birth weight of the offspring (10), chromosomal abnormalities (11), and epigenetic defects linked to imprinting disorders, such as the BeckwithWiedemann and Angelman syndromes (12).

Given the high cost and the even higher psychosocial and physical burden these techniques entail, there is ongoing research to optimize ART outcome, that is, achieve an uneventful pregnancy leading to healthy offspring (13).

Proteomics represents a state-of-the-art, technology-driven science, which in a high-throughput mode studies proteins and their post-translational modifications and interactions and provides the opportunity to elucidate complex biological processes and conditions, including fertilization, embryo 
implantation and differentiation and pregnancy $(14,15)$. The advances in the use of mass spectral (MS) profiling have enabled determination of potential biomarkers and treatment targets in biological tissues and fluids related to human reproduction. This advance may provide substantial information on the various steps of the ART process and might hopefully lead to the successful outcome of high-risk ART pregnancies.

This review presents recent data on MS-based proteomics in humans aiming to identify markers that may optimize ART outcome, beginning from the evaluation of the male and female gamete to the assessment of embryo quality and endometrial receptivity and finally to prevention of pregnancy complications and disorders in the offspring, frequently, but not exclusively, associated with ART.

Proteomics is the descriptive, quantitative and qualitative study of proteins in a biological unit (16). The proteome is not only the sum of proteins that derive from the translation of the genome, as we know that proteins differ significantly in stability and turnover rates, are subject to posttranslational modifications and interact with other proteins to form structural and functional complexes (17). Therefore, the proteomic profile is both multifaceted and dynamic spatially and temporally, as it mirrors different phases of cell differentiation and status.

In current practice, proteomics technology encompasses four clinical applications: i. Mining, protein identification in a specific biologic sample. ii. Protein expression profiling: detection of proteins that characterize a particular state of the organism or cell, such as differentiation stage or disease. Protein expression profiling is achieved through comparison of two different states of the same system, i.e. between normal and diseased tissues or cells. iii. Protein-network mapping: determination of protein interactions within a specific functional protein network and assessment of their status at a specific time point. iv. Mapping of protein modifications: the identification of possible post-translational changes that determine the protein's structure and function, but are also the result of exogenous environmental influences, such as drugs or radiation (18).

\section{Tools Used in Proteomics Analysis}

To approach these goals, proteomics technology includes three major steps:

Analytical protein separation. This step enables the resolution of protein mixtures and simplifies the identification of target proteins that substantially differ in quantity between two samples. The most widely used technique is one (1-D) and -mainly- two dimensional (2-D) electrophoresis. To employ these methods and optimize their results, prior appropriate protein extraction is necessary. In typical 2-D electrophoresis, proteins are separated according to their electric charge (isoelectric point-IP) through isoelectric focusing (IEF) and according to their molecular mass on a polyacrylamide gel containing sodium dodecyl sulfate (SDS-PAGE) and are subsequently visualized through staining (19). Acquired gel images are digitalized and further analyzed through computers for protein volume or intensity quantification (20). Other techniques, such as highperformance liquid chromatography (HPLC) or affinity chromatography, or capillary electrophoresis can be useful tools in analytical proteomics, especially when integrating different protein and peptide separations, as multidimensional techniques (MudPIT) (21).

Mass spectrometry. The analytes that have been isolated based on their IP and their molecular mass (by 2-D electrophoresis) are identified by MS, that-roughly-consists of ionization and subsequent identification of a compound based on the ion mass/charge ratio $(\mathrm{m} / \mathrm{z})$. MS instrumentation has evolved dramatically through the years into a robust and highly reliable tool to analyze proteins and peptides. It can provide accurate mass measurements of large intact proteins $(>100 \mathrm{kDa})$ and small peptides that have been derived from proteolytic digests, as well as sequence analysis of these peptides. The equipment comprises of i) an ionization source, namely matrix-assisted laser desorption/ionization (MALDI) and electrospray ionization (ESI). Other MALDI variants include surface enhanced laser desorption/ionization (SELDI) and imaging MS; ii) a mass analyzer: time of flight (TOF), quadrupole and ion trap (IT) analyzers are those most commonly used. During this step, the ionized components are accelerated while passing through a vacuum chambereither between two electrodes (TOF), four-rod electrodes (quadrupole) or in a three dimensional electric field (IT/Orbitrap), and finally received by the detector that calculates the $m / z$ value. Combinations of these analyzers may be used in order to produce more accurate results. The derived $m / z$ values are processed by a computer and result to the final MS spectrum. The peptide sequence can subsequently be determined after fragmenting selected peptides by collision-induced dissociation or by electron transference and performing a second MS analysis. The final result is a MS/MS spectrum that mirrors a series of distinct amino acids and thus allows the determination of the peptide sequence. MS also enables the identification of posttranslational modifications, such as phosphorylation, glycosylation, acetylation and ubiquitination that lead to a mass increment or mass deficit compared to the naked amino-acid sequence by tandem MS.

Identification. The derived MS spectra are juxtaposed to software, database-searching solutions MASCOT (22), SEQUEST (23) and X!Tandem (24), used to search 
databases (e.g. SwissProt, TrEMBL) containing catalogs of proteins of the organism/cell of interest through sophisticated software that match MS data with specific protein sequences included in these databases. These software tools can also match MS data to sequences in protein, expressed sequence tags and genome-sequence databases and, thus, produce an automated, rapid interpretation of MS results.

Methodologies employed in proteomics are classified as bottom-up, or shotgun proteomics, and top-down types. The former includes LC separation of peptides derived from resolution of protein complexes followed by MS, whereas the latter involves processing of the intact protein, allowing, thus, recognition of posttranslational modifications. Further processing of the samples prior to MS is possible to achieve higher concentrations of low-abundant components of interest. Moreover, MS-identifiable labeling [such as isotope coded affinity tag (ICAT) (25), isobaric tags in isobaric tags for relative and absolute quantification (iTRAQ) (26), stable isotope labeling with amino acids in cell culture (SILAC) (27) and other non-labeling methods have been developed to facilitate the quantification of proteins and peptides (28).

Proteomics have been integrated into the study of human health and disease over the last decade and, in some fields, are now considered an integral part of study design. Almost all biologic fluids (serum, plasma, urine, saliva, cerebrospinal, synovial, bronchoalveolar lavage, and amniotic fluids (AF), as well as tissue samples have been analyzed in search of specific target proteins that may act as possible diagnostic or therapeutic markers. Almost all fields of clinical medicine have profited from the characterization of proteins and their subproteomic profiles, such as the phosphoproteomes, in different tissues and medical conditions, although their use in everyday clinical practice remains a challenge (29-31).

\section{Proteomics and Sperm}

Male factor is believed to account for $50 \%$ of overall infertility $(32,33)$ and the investigation of sperm through MS is of outmost importance to gain a more in-depth insight in its physiology and possible defects in infertile men.

Human testis proteome has been examined in several studies (34-36) that have managed to identify 143, 462 and 725 proteins, respectively, although less than 200 of them are common in all studies, unraveling, thus, the difficulties met by investigators in applying proteomic techniques in tissue biopsies (37). However, more recent studies have managed to yield significant results in further understanding aberrant spermatogenesis. Testis samples from patients with sertoli cell only syndrome (SCOS) were submitted to MALDITOF/TOF MS proteomic analysis to reveal 13 differentially expressed proteins compared to healthy controls. Among them, heterogeneous nuclear ribonucleoprotein L (HnRNPL), which appeared underexpressed in patients, seems to have an important role as regulator of growth and apoptosis of spermatogonia (38).

To overcome technical difficulties, scientific interest has, therefore, mainly focused on the proteomic analysis of semen components, that is, sperm and seminal fluid, for the identification of infertility biomarkers. Several studies have characterized the normal human sperm proteome (39). Some of the research groups have utilized a subcellular approach, aiming to differentially characterize the proteome of sperm surface (40-42), tail (43), both head and flagella (44) and nucleus (45). The bioinformatic analysis of the above studies on human sperm revealed the presence of only 5 proteins that were common in all subcellular sperm structures (RASrelated protein RAB-2A, heat-shock protein 2 (HSP2), valosi-containing protein, lactotransferrin and member B1 of the sperm protein associated with the nucleolus on the $\mathrm{X}$ chromosome family). Moreover, the datasets provided by these studies provided an almost complete estimation of the entire sperm proteome (37). More recently, Amaral et al. compiled a list of 6,198 different proteins identified in human sperm, functionally involved in metabolism, apoptosis, cell cycle, meiosis, RNA metabolism and translational regulation, as well as proteins of cytoplasmatic ribosomes and peroxisomes (46). Proteomic analysis of human sperm samples after chromatin fractionation has revealed two sets of proteins with differential affinity to chromatin (regulatory proteins: weakly attached versus structural proteins: strongly attached) that may reflect their epigenetic role (47).

Post-translational modifications, and especially phosphorylation, are considered critical in the course of spermatogenesis and establishment of normal sperm function, as indicated by the high phosphorylation levels in the testis (48). Whilst attempting to characterize the sperm proteome using MS analysis, Shetty et al. recognized the presence of the same protein in different, distinct 2-D-gel spots, describing, thus, the eventual post-translationally modified protein forms (49). In the study by Ficcaro et al., who performed 2-D gel analysis coupled to antiphosphotyrosine immunoblots, followed by tandem MS, valosin-containing protein and two members of the A kinase-anchoring protein family (AKAP3 and AKAP4) were found to be tyrosine-phosphorylated during sperm capacitation (50). The use of label-free quantitative phosphoproteomics has revealed 231 sites of increased phosphorylation in human sperm during capacitation, mediated through the insulin-like growth factor receptor (51). Lefièvre et al. explored the role of nitrous oxide in human sperm function, identifying not only well-established targets for S-nitrosylation in other cells, but also spermspecific new targets, including AKAP3 and -4, voltagedependent anion-selective channel protein 3 and 
semenogelin 1 and 2 (52). The role of lysine acetylation in fertilization has been studied by Sun et al., who used LCMS proteomic analysis to unravel 576 lysine acetylated proteins in human capacitated sperm. The inhibition of lysine deacatylases seemed to have a negative impact on sperm motility and, thus, fertilization. Other proteomic studies have attempted to elucidate the roles of posttranslational modifications in defective sperm and will be discussed below.

The use of MS in the identification of fertility markers in human sperm is gaining the attention of investigators worldwide. Pixton et al. in 2004 relied solely on 2-D electrophoresis to compare the proteomic profile of the sperm of a man that had been previously employed in unsuccessful IVF with that of three fertile donors (53). They were able to recognize 20 spots that were consistently expressed differently, among which secretory actin-binding protein and outer dense fiber protein $2 / 2$ were identified. De Mateo et al. analyzed 47 sperm samples from infertile men and 10 fertile donors by 2-D gel electrophoresis followed by MALDI-TOF analysis to quantify the expression of 101 spots. Of the identified proteins, eight correlated with DNA integrity and seven with protamine content, constituting, thus, possible markers of sperm quality (54). The same group identified 17 differentially expressed proteins in the sperm samples of asthenozoospermic men, which were consistently associated with the asthenozoospermic samples (55). Members of the heat shock protein firing (HSPs) were recognized in both studies. The roles of HSPs were further implicated in impaired sperm-oocyte recognition in the study of Redgrove et al. (56). MS-based quantification was applied to compare proteomic profiles of normal spermatozoa and spermatozoa exhibiting such impairment and revealed reduced expression of heat-shock 70-kDa protein 2 (HSPA2), which appears to have a critical role in sperm-oocyte interaction and is possibly related to the underlying mechanism(s) of male infertility (56). A number of studies have proteomically analyzed asthenozoospermic samples aiming to clarify the molecular basis of sperm motility. Zhao et al. identified 10 proteins differentially expressed between asthenozoospermic men and normal controls (57), whereas 16 differentially expressed proteins were identified by MALDI-TOF tandem MS in the study by Shen et al. (58).

Comparative proteome analysis between asthenozoospermic and normozoospermic patients by Siva et al. identified eight proteins, functionally involved in cellular metabolism (triosephosphate isomerase, glycerol kinase 2 and succinyl-CoA:3ketoacid co-enzyme A transferase 1), movement (tubulin beta $2 \mathrm{C}$ and tektin 1), as well as the stress response (proteasome alpha 3 subunit and HSPA2). Interestingly, the proteins of the first group were overexpressed in the asthenozoospermic samples in contrast to the proteins of the two other groups that were underexpressed. A positive correlation was noted between proteasome alpha 3 subunit levels and rapid, linear progressive motility of the spermatozoa (59). Semenogelin II precursor, prolactininduced protein, clusterin isoform 1, and prostate-specific antigen isoform 1 pre-proprotein were overexpressed in the sperm of fertile compared to that of infertile men in the study by Thacker et al. Semenogelin II precursor and clusterin isoform 1 were absent in the infertile sperm samples, indicating a particular importance of these proteins in male fertility (60). Another study identified 24 differentially expressed proteins between fertile and infertile men with normal sperm parameters, mainly involved in wound healing, metabolism and cell growth and even managed to reconstruct a functional network including nine out of the 24 proteins (61). More recent studies have focused on the differential proteomic sperm analysis between men that achieved pregnancy through IVF and those with a history of unsuccessful IVF attempts. In the study by Frapsauce et al., complete failure to achieve sperm binding to the oocyte and consequently oocyte fertilization in men with normal sperm parameters was investigated in comparison to men that had been associated with successful IVF. Out of the 12 proteins that were identified by MS, laminin receptor LR67 and L-xylulose reductase seem to be involved in sperm-oocyte interaction (62). Finally, spermatozoa from six men who failed and six who succeeded in achieving clinical pregnancy through IVF were submitted to proteomic analysis through 6-plex tandem mass tag (TMT) isobaric MS and were compared. Of the 21 proteins that differed between the two groups, three (A2LD1, ATP1B3 and FBXO2) exhibited a more consistent pattern (63). Azpiazu et al. used LC-MS/MS after TMT labeling to identify differentially expressed proteins in the pooled sperm samples from 10 normozoospermic men who failed to achieve pregnancy and that of 10 normozoospermic men who achieved clinical pregnancy. Sixty-six proteins were found to be either over- $(n=35)$ or under-expressed $(n=31)$, mainly involved in chromatin assembly and lipoprotein metabolism.

The proteomic profiles of fertile men, normozoospermic men with infertility and normozoospermic men who have failed to achieve pregnancy after IVF were compared after iTRAQ labeling and LC-MS analysis. Of the 18 proteins that were found to be differentially expressed between the fertile and the two infertile subgroups (aggregated), semenogelin 1 (SEMG1), prolactin-induced protein (PIP), glyceraldehyde-3phosphate dehydrogenase (GAPDHS), and phosphoglycerate kinase 2 (PGK2), were found to be common in the two infertility subgroups. The sperm proteomic profile of normozoospermic men undergoing an ICSI procedure for non-male factor infertility was compared with regards to satisfactory blastocyte development and-consequentlybetter implantation rate. Forty nine proteins were identified 
to be differentially expressed between the two groups (good versus poor blastocyte development), including HSPs and spermatogenesis involved proteins. Interestingly the samples were not different according to the classical morphological, functional and quantitative criteria that are currently applied (64).

In regard to post-translational modifications, the phosphoproteomic profiles from eight normozoospermic and asthenozoospermic samples that were derived from ultraperformance LC/MS were investigated in search of underlying mechanisms that regulate/compromise sperm motility. The majority of the 66 phosphoproteins that were differentially expressed in asthenozoospermia were HSPs, cytoskeletal proteins, proteins related to the fibrous sheath and proteins involved in cell metabolism. Further structural and functional pathway analysis of these spermatozoa confirmed the defects suggested by the differential proteomic profiling (65). Finally, Vigodner et al. localized areas of increased SUMOylation (small ubiquitin-like modifiers) in specific regions of morphologically abnormal human sperm. Through MS they managed to identify 55 SUMOylated proteins, such as HSPs, proteins involved in metabolism, sperm maturation -some of which were sperm-specific-, including HSPA2, A-kinase anchor proteins 3 and 4, Llactate dehydrogenase $\mathrm{C}$, valosin-containing protein and seminogelins (66). Despite the increasing number of studies on spermatozoa, the majority of proteomic analyses have been conducted on seminal plasma (SP), which comprises $90 \%$ of the semen and is the supernatant remaining after centrifugation of the semen (67).

The application of MS following gel electrophoresis resulted in identification of 42 proteins in a pooled normal human SP sample by Fung et al. in 2004 (68). Pilch and Mann in 2006 managed to identify 923 proteins from a single sample, further elucidating the proteomic profile. Among these proteins, those more abundantly expressed were fibronectin, semenogelin 1 and semenogelin 2 (involved in gel formation, also identified by Fung et al.), lactoferrin (involved in protection from infections), laminin and serum albumin (69). In a more recent study Milardi $e t$ al. performed proteomic analysis using a LTQ Orbitrap XL hybrid MS of the seminal plasma of five fertile men who has recently achieved pregnancy. A total of 919 to 1,487 proteins were identified in each sample, of which 83 were common. Among them, semenogelin 1 and 2, olfactory receptor 5R1, lactoferrin, hCAP18, spindling, and clusterin are believed to be involved in male fertility and, therefore, present a special interest as potential biomarkers (70). Previously, StaritaGeribaldi et al. had identified prostatic acid phosphatase and prostate specific antigen in the SP of a fertile man and also proceeded to the comparison of the electrophoresis gels from five normal SP samples to those from vasectomized, anorchid and SCOS patients to recognize a number of common spots missing in the group of men with impaired spermatogenesis (71). Yamakawa et al. isolated 63 common spots from 10 fertile men and compared them to those from the gels of both obstructive (OA) and non-obstructive azoospermic (NOA) patients. By LC-MS/MS analysis they managed to identify 6 spots that may be used as potential markers to differentiate OA and NOA, including epididymal secretory protein 1 , stabilin $2,135-\mathrm{kDa}$ centrosomal protein, guanine nucleotide-releasing protein and prolactin-inducible protein (72). Batruch et al. utilized MudPIT and high resolution MS to proteomically characterize the seminal plasma of both normal donors and vasectomized azoospermic men and subsequently compared the derived profiles to those of men with non-obstructive azoospermia, to identify 18 and 59 proteins that were overexpressed, as well as 34 and 16 proteins that were underexpressed in the NOA group compared to controls and PV, respectively, allowing, thus, possible discrimination between $\mathrm{OA}$ and NOA patients. Two of these proteins, SPAG11B and TEX101, were considered highly important as infertility biomarkers $(73,74)$. In a more recent study by Drabovich $e t$ al. immunohistochemistry and an immunoenrichment MSbased assays were utilized in SP samples of azoospermic and normal men and succeeded in recognizing epididymisexpressed ECM1 and testis-expressed TEX101 as highly specific and sensitive markers differentiating obstructive and non-obstructive azoospermia (75). Seminal plasma from asthenozoospermic men (AS) was compared to that of healthy donors in the study by Wang et al. Of the 741 identified proteins, 45 proteins were up-regulated and 56 proteins were down-regulated in the AS group. Those more prevalently overexpressed included fructose-bisphosphatealdolase A, glyceraldehyde-3-phosphate dehydrogenase, legumain precursor and epididymal-secretory protein E4, whereas the most underxpressed protein was DJ-1, a protein known to reduce oxidative stress (76). Kumar et al. dedicated part of their work in the clarification of the role of heparin-binding proteins (HBPs), including semenogelin 1 and 2, lactoferrin, PSA, bovine seminal plasma proteins, zinc-finger protein and fibronectin, as possible biomarkers of male infertility. More recent proteomic analysis using isoelectric focusing (IEF) followed by MALDI TOF/MS identified $40 \mathrm{HBSs}$, mainly involved in metabolism, RNA transcription/ transport, cell transport, recognition and signaling (77). Davalieva et al. recognized fibronectin, proteasome subunit alpha type-3, beta-2-microglobulin, galectin-3-binding protein, prolactin-inducible protein and cytosolic nonspecific dipeptidase as differentially expressed proteins in azoospermic sperm when compared to at least one of the three control groups, namely normozoospermic, asthenozoospermic and oligozoospermic men. The only protein that was significantly overexpressed in comparison to all three groups was prostatic acid phosphatase (78). 
Sharma et al. also performed LC-MS/MS in 4 groups of patients taking into account both sperm count (normozoospermic and oligozoospermic) and sperm morphology (normal and abnormal). Of the 20 identified proteins that were differentially expressed, 3 were downregulated solely in the Normal count-Abnormal morphology group (mucin 6, cystatin $\mathrm{S}$ precursor, prostatic acid phosphatase precursor), one (clusterin isoform) was downregulated and two (zinc alpha-2 glycoprotein 1, tissue inhibitor metalloprotease 1 precursor) were up-regulated in the oligozoospermic-normal morphology group, whereas one (cystatin C precursor) was down-regulated and two were upregulated (prostate-specific antigen isoform 1 pre-protein, semenogelin 1 isoform $b$ pre-protein) in the oligozoospermic-abnormal morphology group) respectively in comparison to the normal controls (79). The same group compared the proteomic profile in SP samples from both fertile and infertile men that were further categorized according to levels of reactive oxygen species (as a measure of oxidative stress), to identify 10 overexpressed and five underexpressed proteins in the group with reactive oxygen species, involved mainly in protein metabolism modification and oxidative stress regulation (80). Finally, Hedwig et al. identified 24 proteins that were up-regulated in the SP samples of 11 males with idiopathic oligoasthenozoospermia compared to healthy controls. Five of them were common across all samples. The same study has further expanded our knowledge on human SP proteomic profile by recognizing a total of 2,489 proteins (81). In a recent study by Intasqui et al. proteomic results have been studied in relation to classic methods of sperm evaluation: sperm mitochondrial activity, acrosome integrity and sperm fragmentation. The authors propose annexin A7, endoplasmic reticulum resident protein 44 and glutathione S-tranferase Mu3 as biomarkers of mitochondrial activity and phospholipid transfer protein, a protein involved in the regulation of phospholipid exchange in lipoproteins, as a marker of acrosome integrity. The also propose cysteine-rich secretory proteins-involved in cellular adhesion- and retinoic acid receptor responder protein1, a tumor suppressor, as markers of low fragmentation rate and proteasome subunit alpha type-5, a protein involved in protein degradation, as a marker of increased fragmentation and, thus, subefertility, respectively (82).

\section{Proteomics and Oocyte}

Human follicular fluid. Human follicular fluid (HFF) constitutes the natural environment of the oocyte containing a vast network of dynamically changing proteins responsible for its growth and development that ultimately affect its quality and fertilization potential (83). Moreover, it is an easily accessible biological fluid, as it is aspirated in abundance at the stage of oocyte retrieval during ART procedures and has been proven to be a useful substrate for proteomic analysis aiming to delineate its exact composition and functionality, as well as to identify valid biomarkers of ART outcome.

Over the last years, several study groups have published their work on the proteome of HFF of women undergoing ART procedures. Schweigert et al. applied SELDI-TOF-MS to compare paired samples of plasma and FF from women undergoing IVF and managed to reveal different protein patterns that may be attributable to the changing bloodfollicle permeability during oocyte maturation and indicate selective transport (84). In agreement with these results, the study of Angelucci et al. recognized a high concentration of proteins involved in inflammatory processes, including transferrin, ceruloplasmin, haptoglobin and plasma amyloid protein, as well as antioxidant enzymes, such as catalase, superoxidase and HSP27, solely present in the follicular milieu and not the plasma in 25 normo-ovulatory women, further supporting the inflammatory characteristics and oxidative stress involved in follicle maturation (85). Twigt et al. attempted to describe the proteomic profile of HFF by comparing two different approaches: SDS-PAGE and in-tube gel digestion and prefractionation of proteolytic peptides, both followed by reversed-phase LC-MS/MS. They managed to identify 246 proteins, most of which were primarily linked to coagulation and the inflammatory reaction. The prefractionation approach was more efficient in detecting proteins (86).

In a recent study by Bianchi et al. in the follicular fluid of six women undergoing IVF after ovarian hyperstimulation, 43 unique proteins were identified, functionally classified in 5 groups (inflammation and regulation of acute-phase, complement and coagulation, response to wounding, protein-lipid complex/lipid metabolism and transport, and cytoskeleton organization) and cross-linked to generate a tightly controlled pathway depicting the initial inflammatory-like phase of ovulation, also described in previous studies $(87,88)$, further accentuated by ART superovulation, followed by tissue remodeling that is crucial for the formation of corpus luteum. A1 antithrypsin was differentially expressed in the follicular fluid and sera of women in this cohort (89). A more recent study by $\mathrm{Wu}$ et al. further confirmed the previous results, by using 2-DE MALDI-TOF-MS to compare the HFF proteomic profile of women subjected to controlled ovarian hyperstimulation and women to natural cycles. The analysis identified eight differentially excessed proteins, among which transferrin, complement component C3 (C3), haptoglobin and alpha-1-antitrypsin (90).

In an attempt to recognize positive predictive markers of an ART attempt, Jarkovska et al. used comparative proteomic profiling in plasma/serum and FF from women undergoing successful IVF and found altered expression of functional components of the complement cascade, as well as proteins 
involved in angiogenesis and blood coagulation (91). FFs from 10 pairs of women with successful and unsuccessful IVF outcome were compared in the study by Estes et al. to demonstrate 11 potential biomarkers including haptoglobin alpha, mitochondrial integrity genome (ATPase), apolipoprotein $\mathrm{H}$, dihydrolipoyl dehydrogenase, lysozyme $\mathrm{C}$, fibrinogen alpha-chain and immunoglobulin heavy chain V-III (increased) and antithrombin, vitamin D-binding protein, and complement 3 that were decreased in the second group (92). In the study of Severino et al., iTRAQ labeling, off-gel peptide pre-fractionaction followed by LC-MS/MS analysis lead to the identification of 89 differentially expressed proteins in the HFF from successful and unsuccessful IVF procedures. The applied techniques have also enabled the identification of a number of low-abundance proteins. The results of the study have further confirmed the principal role of immune response, coagulation and acute-phase reaction in IVF.

In a recent study by Ambekar et al., 320 previously unreported proteins were identified after proteomic analysis of FF in six healthy women and subsequent comparison with previous studies. In addition, nine out of these 320 proteins (tumor necrosis factor, alpha-induced protein 6, angiogenin, ribonuclease, RNase A family 5, fibronectin 1, serpin peptidase inhibitor clade $\mathrm{E}$, pentraxin 3, glutathione peroxidase 3, cathepsin B, superoxide dismutase and multimerin 2) were previously reported markers of oocyte quality and IVF outcome. The majority of the identified proteins were functionally classified in extracellular matrix proteins, components of inflammation and coagulation, proteins involved in angiogenesis and, mostly, enzymes (93).

Finally, HFF comparative proteomic analysis (2-DE MALDI-TOF MS) of young and older women has identified five downregulated proteins in the older group (serotransferrin, hemopexin precursor, complement C3, C4 and kininogen), that may be considered of markers of reproductive aging and possibly infertility (94).

Cumulus cells. During oocyte collection, mature oocytes are surrounded by cumulus oophorus cells (COC) that play an important role in regulation of oocyte maturation (95). Moreover cumulus cell morphology, as evaluated by microscopic observation, is also considered to relate to the fertilization capacity of the oocyte (96). Hamamah et el. utilized comparative proteomic profiling from the COCs of patients that had undergone different IVF protocols and with different outcomes. Protein expression profiles differed significantly in COCs deriving from diverse protocols even when fertilization outcome was the same. Similar results were obtained even when different protocols were applied on the same patient, affirming, thus, a potential role for proteomically derived markers in adjusting ovarian stimulation protocols to achieve improved oocyte fertilization rates (97). In a more recent study by Braga et $a l$., LC-MS proteomic profiling of human COCs of patients undergoing ICSI revealed a panel of exclusively expressed proteins in ova progressing to the blastocyst stage, as well as in those reaching pregnancy, underlining the possible predictive role of proteomics (98).

\section{Proteomics and Embryo Quality}

The use of proteomics in ART technologies goes beyond the simple recognition of the quality of the gametes, which is just the initial stage in ART procedure. The in vitro formation of the zygote and its gradual development and maturation prior to embryo transfer in the endometrial cavity is a period that not only allows, but is also highly suitable for the application of non-invasive techniques that can timely and accurately distinguish good quality embryos, with increased potential to result in healthy offspring, avoiding, thus, multiple embryo transfers and increased rates of unsuccessful implantations, prematurely terminated pregnancies or the birth of a sick child. Currently, embryo assessment mainly relies on embryo cell number and morphology, with additional co-evaluation of other parameters, such as maternal age or basal FSH levels. However, the introduction of novel techniques has enabled the identification of supplementary markers. These include biochemical measurements in the embryo culture media, assessment of oxygen consumption by the embryo, and mainly- the utilization of genomics, widely encompassed in preimplantation genetic diagnosis, metabolomics of embryo media culture and proteomics $(99,100)$.

Initial proteomic studies performing HPLC in the embryo culture media of 53 ICSI cycles recognized a significant correlation of the turnover of amino acids asparagine, glycine and leucinewith clinical pregnancy and live birth rate, regardless of classic predictors, such as female age, follicle-stimulating hormone levels, embryo cell number and embryo morphological grade (101). The introduction of MS has amplified not only the possibility of identifying biomarkers of embryo viability, but also of deciphering the underlying mechanisms that regulate embryo development and has, hence, been used in numerous studies. Katz-Jaffe et al. managed to synthetize distinct proteomic profiles, using SELDI-TOF MS, which allowed differentiation of the stages of embryonic development from fertilization to the blastocyst stage. Moreover, ubiquitin was identified as a possible biomarker of blastocyst development potential (102). The same technology was utilized by the same group to obtain and compare the proteomic profiles of early, expanded and degenerating blastocysts, to find differential protein expression between the different blastocyst developmental stages. Possible biomarkers included proteins mainly involved in apoptotic mechanisms and signaling inhibition (103). In another study, spent culture media 
samples that were used during ICSI procedures were divided into two groups according to whether embryos were successfully implanted and subsequently subjected to nanoultra-high pressure chromatography for protein separation, followed by protein identification via tandem nanoelectrospray ionization MS with a hydrid Qq-TOF MS. The protein that was most frequently detected in the successful implantation group was jumonji (JARID2), a component of the polycomb repressive complex 2 (PRC2), which is related to gene silencing through chromatin modifications, whereas in the unsuccessful implantation group, TSGA10. a perinuclear protein which is believed to enhance gene expression, was most frequently identified (104). Twodimensional gel electrophoresis in combination with MS/MS was applied on spent culture media from human preimplantation embryos by Mains et al. Increased levels of apolipoprotein A1 (APOA1) identified in the embryonic secretome were associated with blastocysts of a higher morphological grade, but did not seem to have an impact on final IVF outcome (105). Finally, lipocalin-1, a protein that is increased in inflammatory and stress conditions, also known to inhibit embryo implantation, was overexpressed in both pooled and individual secretomes of blastocysts that had been identified as aneuploid by previous chromosome screening investigation, rendering it a potential noninvasive biomarker for aneuploidies, which remains to be further validated (106).

In a very interesting study, LC-MS/MS analysis was used to analyze the proteomic profiles of commercially available culture media after albumin depletion. Tha proteomic analysis of human purified serum albumin that is added in all culture media suggested that a number of proteins, mainly involved in immune response and inflammation, are concomitantly introduced to the media during addition. This observation complicates the interpretation of the results from proteomic studies on spent culture media, but also raises questions regarding the impact of the identified proteins on embryo development (107).

In a recent study by Poli et al., embryo quality was assessed by performing proteomic analysis of the blastocelic fluid, that is, the content of the cavity surrounding the fully developed blastocyst, immediately prior to implantation, in 145 human embryos donated by couples undergoing ART, aiming at a more representative profiling of viable embryos compared to the culture media profiling that has been used so far. To that end, they used urea-based and Mono-Prep tandem MS (Orbitrap system) and subsequently confirmed the embryonic origin of 182 of the identified proteins by gene-expression analysis. Finally, two of the most abundant peptides were quantified using selected reaction monitoring assays to reveal statistically signicant differences in the levels of GAPDH and H2A protein family across euploid and aneuploid groups (108).

\section{Proteomics and Endometrial Receptivity}

Aberrant endometrial receptivity is one of the major causes of female infertility and ART failure and has justifiably gained attention as potential source of biomarkers to help reduce unsuccessful ART cycles (109). Proteomic profiling of human endometrium during the proliferative and secretory phase led to the identification of five proteins with altered expression, of which glutamate NMDA receptor subunit zeta 1 precursor and FRAT1 were differentially expressed in the secretory endometrium in the study of DeSouza et al. (110). A similar comparison by Chen et al. identified 76 differentially expressed proteins, of which 34 were isoforms of different charge or size, indicating marked post-translational modifications and processing (111). Hood et al. performed a global quantitative MS proteomic analysis in both epithelial and stromal cells during the proliferative and secretory phase and managed to identify 318 and 19 differentially overexpressed proteins between phases in the uterine epithelium and stroma, respectively. Further immunohistochemical techniques were applied to a subset of these proteins in order to elucidate eventual modifications during the menstrual cycle (112). MALDI/MS profiling in endometrial biopsies from the 16th to the 21 st day of the menstrual cycle (implantation window) in eight fertile women identified annexin A2 and stathmin as possible markers of the receptive capacity of the endometrium (113). Superimposition of the results of proteomic and transcriptomic studies revealed that annexin A was actually the only gene to be consistently overexpressed and for which mRNA abundance is translated to a protein abundance (114). Parmar et al. analyzed endometrial tissue during the mid-secretory phase and compared the derived profiles with profiles of uterine fluids from the same period and endometrial biopsies of the proliferative phase and demonstrated increased concentrations of calreticulin, the beta chain of fibrinogen, adenylate kinase isoenzyme 5 and transferrin in the proliferative phase and of annexin $\mathrm{V}$, alpha1-antitrypsin, creatinekinase, and peroxidoxin 6 in the midsecretory. HSP27, transferrin and alpha1-antitrypsin precursor were abundant in both endometrial tissues and uterine fluid (115). Garrido Gomez et al. applied differential in-gel electrophoresis followed by MALDI-MS to investigate the proteomic differences between the receptive and non-receptive endometrium on the 5th day after progesterone administration during an IVF cycle and recognized 24 differentially expressed proteins, among which progesterone receptor membrane component 1 and annexin A6 seem to have a significant role in endometrial receptivity (116). Finally, Meng et al. studied the differential effect of GnRH antagonist based protocols of ovarian stimulation compared to GnRH agonist based protocols and natural cycles on endometrial receptivity during ICSI 
procedures, in order to examine their efficiency, using iTRAQ quantification analysis. Seven proteins, including ACO2, CDC5L, GNAS, ARF1, ANPEP, SERPIND1 and SEC23B were differentially expressed exclusively in the $\mathrm{GnRH}$ antagonist group. According to the subsequent bioinformatic analysis, these proteins are mainly involved in angiogenesis, cell cycle, apoptosis, cell migration, cell proliferation and immune response (117).

The most important difficulty encountered during proteomic analyses of tissue biopsies was the high abundance of many functional and structural proteins in the collected samples that hindered the identification of other proteins that are present at significantly lower levels. Moreover, existent gel techniques do not facilitate the separation of proteins of low molecular weight. Investigators suggest pre-fractionation of samples and use of gel-free techniques to overcome these two major limitations and possibly identify more biological markers (118).

In fact, a substantial number of studies have focused on the less invasively accessible uterine fluid in order to retrieve useful biomarkers. Casado-Vela et al. attempted an extensive characterization of the human endometrial secretome by combining three different techniques and succeeded in recognizing 803 proteins (119). Hannan et al. studied the endometrial secretome of seven fertile women during both the mid-proliferative and mid-secretory phase and compared it with that of eight infertile women only during the mid-secretory phase. The comparison identified seven proteins that were significantly more highly expressed during the mid-secretory phase in the first group, whereas 18 spots showed differential expression (12 were increased and six were reduced) between the two groups of patients that subsequently needed to be further investigated concerning their functionality (120). Similarly, Scotchie et al. identified 42 differentially expressed proteins in the uterine fluid in the pre-receptive and receptive state of the endometrium. Many of these proteins are functionally involved in the immune and inflammatory reaction, the stress response and apoptosis, indicating the importance of the immunological processes that take place to achieve implantation and pregnancy. Alpha-1 antitrypsin was common to all three studies, with lower levels being observed in the mid-secretory phase. Antithrombin III and alpha-2-macroglobulin were further examined in the midsecretory tissue, where they followed the same pattern of change across the cycle as that observed in the uterine fluid (121). Recently, Bhutada et al. examined the role of high mobility group box 1 (HMGB1), a protein that was found to be differentially overexpressed in the pre-receptive phase in comparison with the receptive phase after 8-plex iTRAQ analysis of the human uterine fluid. Further analysis an animal models has revealed that HMGB1 abundancy is associated with pregnancy termination, suggesting thus a possible harmful effect of high HMGB1 levels on receptivity (122). In a very recent study by Bhagwat et al. proteomic analysis in two human endometrial epithelial cell lines with known differential adhesiveness to embryo cells revealed differential expression of 55 proteins. Among the 10 identified proteins, CRT and HSPA9 appear to promote adhesiveness, whereas TUBB2C seems to hinder it (123).

\section{Proteomics and ART Outcome}

A large part of the current literature has been dedicated to the study of ART pregnancies and the health of ART offspring. Although some of the included studies do not involve ART populations, their results may be of utmost importance in the prevention of common complications of ART pregnancies and disorders frequently reported in children born after ART.

Zhang et al. analyzed the placentas of six IVF pregnancies, six ICSI pregnancies and six natural conceptions (NC) and identified seven up-regulated and two down-regulated proteins in the IVF group, as well as nine proteins that were up-regulated and seven that were downregulated in the ICSI group compared to the NC group. Five of the identified proteins, namely ATP5A, hnRNPC1/C2, FTL, a-SNAP and annexin A3, were identified in both ART groups, showing a common pattern of modifications. The majority of these proteins were functionally involved in membrane fusion, energy metabolism, mRNA functions, stress response and cytoskeleton (124).

A list of 15 potential proteomic biomarkers of preterm labor in AF and maternal serum identified in more than two studies has been presented in the systematic review by Galazis et al. The proteins included in this list were eutrophil defensin-1 precursor, neutrophil defensin-2 precursor, calgranulin $\mathrm{A}$, calgranulin $\mathrm{B}$, calgranulin $\mathrm{C}$, IGFBP-1 (proteolytic fragment precursor), APOA1, retinol binding protein, filamin $\mathrm{A}$, macrophage-capping protein, neutrophil gelatinase-associated lipocalin precursor, myeloperoxidase precursor/MPO isoform $\mathrm{H} 17$ of myeloperoxidase precursor, FALL-39 precursor, leukocyte elastase inhibitor and Von Ebner's gland protein precursor. A total of 201 potential biomarkers had been previously reported in review articles. Of special interest is the fact that the authors juxtaposed this list to biomarkers of polycystic ovary syndrome, which is not only related to preterm delivery but also to subfertility, and formed a list of six common biomarkers, including pyruvate kinase M1/M2 (PKM1/M2), vimentin, fructose bisphosphonate aldolase A, HSPbeta-1, peroxiredoxin-1 and transferrin (125). Integration of previously reported "classic" biological markers (126) with newly-discovered peptides, isolated through maternal serum proteomic profiling at 28 -week gestation led to a sensitivity of $86.5 \%$ and specificity of 
$80.6 \%$ in the diagnosis of preterm birth (127). Comparative proteomic profiling of placental membranes in term and preterm deliveries revealed a total of 11 proteins either uniquely present in or absent from the placenta of preterm deliveries with complete reproducibility, that were recognized as structural/cytoskeletal components, enzymes and chaperones of the endoplasmic reticulum, as well as proteins with anticoagulant properties (128). In a more recent study, a gel-free TMT-labeling processing followed by LC-MS/MS proteomic of five placental villous tissues from women with early pregnancy loss has resulted in the identification of 51 differentially expressed proteins compared to normal placentas. The identified proteins were mainly involved in cell migration, RNA metabolism, cell differentiation, proliferation, metabolism and apoptosis, as well as reactive oxygen species generation and oxidative stress (129). Several proteomic studies have been conducted in search of early, fetal markers of aneuploidies. Although existent data do not pertain to fetuses conceived after ART, their applicability on ART pregnancies is of major importance, given the advanced age of parents involved $(130,131)$.

The proteome of placenta from 19 patients with Down syndrome (DS) fetuses and 17 normal pregnancies was investigated by 2D-DIGE, followed by MALDI TOF/TOF high-resolution tandem MS, that resulted in the identification of 12 protein spots. Of those overexpressed in DS placentas, superoxide dismutase 1 , endoplasmic reticulum protein 29 and HSPbeta-1 were in involved in reactive oxygen species generation and neurogenesis, while peroxiredoxin-6, a protein with antoxidant properties, was overexpressed in the normal pregnancies (132).

Supernatant AF specimens were analyzed by Wang et al., who managed to discriminate 20 aneuploid from 60 healthy fetuses using a two-step proteomic approach with $100 \%$ sensitivity and $72-96 \%$ specificity in two groups of participants (133). Comparative MALDI-MS and micro-ESI MS/MS in supernatant AF of 6 pregnancies with DS and 12 chromosomically normal pregnancies by Tsangaris et al. led to the identification of five proteins (alpha-1-microglobulin, collagen alpha 1(I) chain, collagen alpha 1 (III) chain collagen alpha 1 (V) chain d, and basement membranespecific heparin sulfate proteoglycan core protein) that were upregulated, one protein (insulin-like binding protein 1 precursor) that was down-regulated and one protein (Splicing factor arginine/serine-rich 4) that was only expressed in pregnancies of fetuses with trisomy 21 or DS (134). Differential expression of nine proteins (TTHY, CERU, AFAM, AMBP, APOE, SAMP, HRG A1AT and CLUS) was also identified in the plasma of mothers carrying DS fetuses by Kolialexi et al. (135), in an attempt to promote the use of proteomics in non-invasive prenatal diagnosis of karyotype abnormalities, a concept that was introduced by Nagalla et al., who successfully discriminated DS from normal pregnancies, identifying 10 proteins that were differentially expressed in both the first and second trimesters of pregnancy, as well as 19 and 18 proteins specific for each trimester, respectively (136). Proteomic profiling revealed altered expression of seven proteins (increased expression of serotransferrin, lumican, plasma retinol-binding protein and apolipoprotein A-I versus decreased expression of kininogen, prothrombin, and apolipoprotein A-IV) in the AF of Turner syndrome pregnancies (137), followed by the identification of nine proteins (C1S, CO3, CLUS, AFAM, HABP2, IGHA1, HPT, SHBG, and CD5L) and three proteins that were decreased in the plasma of mothers carrying fetuses with Turner syndrome by the same group (138).

Umbilical cord blood (UCB) samples from six women with DS fetuses and 11 normal pregnancies were subjected to iTRAQ analysis that identified 505 proteins involved mainly in protein binding, hydrolase activity, nucleotide binding, oxidoreductase activity and lipid binding. Of those, 13 were found to be up-regulated in DS samples and six were down-regulated. APOE, complement factor B (CFB), amyloid P component), serum (APCS) (up-regulated), matrin-3 and osteopontin (down-regulated) were previously associated with DS (139).

Finally, proteomic profiling of umbilical cord blood from 10 intrauterine growth restricted (IUGR) neonates revealed absence of the O-linked sialic acid in single and heavy chain forms of fetuin A, a glycoprotein involved in fetal growth, in vitro cell proliferation and cellular protection versus Gram-negative bacterial toxin, indicating a possible mechanism of impaired intrauterine development and further establishing the use of proteomics in detecting posttranslational modifications of clinical significance (140). Cecconi et al. investigated the presence of markers of IUGR by using 2-DE and nanoHPLC-Chip/MS technology to analyze the proteomic profile of UCB and AF of 10 IUGR and 10 normal pregnancies. Functional classification of the identified differentially expressed proteins (14 in UCB and 11 in AF)revealed the principal role of inflammatory and immune response in the mechanisms of intrauterine growth impairment. Interestingly, the other proteins were related to iron and copper homeostasis, blood pressure, and coagulation, all components of the metabolic syndrome, which is a known long-term consequence of IUGR in adult life (141). Finally, a more recent study explored the proteomic profile of IUGR placentas through TMT-labeling, to reveal 95 differentially expressed proteins compared to placentas from normal pregnancies (142).

The application of proteomics in the characterization of the physiology and the pathology of the human reproductive system has the potential to provide the necessary markers that will render assisted reproduction technologies significantly 
more successful, both by identifying the cause of infertility and providing the possibility of a personalized treatment, but also by contributing to the selection of the most suitable gametes and subsequently the most suitable embryo that will lead to an uncomplicated pregnancy and the birth of healthy offspring. Furthermore, proteomics may also be implicated in identifying early biomarkers of disease in children born after ART, especially since classical and, recently, metabolomic studies have shown subtle differences between naturally conceived children and children born after ART (143-147). As mentioned above, infants born by ART are at a higher risk for IUGR and being born small for their gestational age (148). These conditions are well known to predispose to adult disease and to be associated with an unfavorable cardiometabolic profile in later life $(149,150)$. This alone could raise concern about the long-term health issues of children born after ART and may explain the recently observed poor cardiometabolic outcome of ART children (151). Moreover, hormonal hyperstimulation (152), in vitro culture conditions (153), manipulations of the gametes and the blastocyst (154), have been shown to cause alterations in the imprinting status of some genes, indicating an effect on epigenetic reprogramming that could be a potential mechanism for alterations in growth, development and metabolism of ART children (155). Increased parental stress and consequently increased glucocorticoid production, as well as endometrial oxidative stress conditions, amplified by hormonal hyperstimulation, may further contribute to an adverse intrauterine environment, which induces epigenetic and constitutional changes that impair the metabolic profile later in life $(156,157)$. Proteomics have already been introduced as a useful tool in the characterization of the plasma/serum proteome for the discovery of next-generation markers for risk assessment, early or even prenatal diagnosis and prognosis of metabolic disease $(158,159)$ and may be expected to provide a new insight in the metabolic profile of ART children.

\section{Concluding Remarks}

Despite the constant advancements in the field of ART, the specific factors that decisively contribute to a positive outcome still remain to be elucidated. The innate complexity of human reproduction and fertility, further enhanced by the effect of extrinsic factors, such as hyperstimulation protocols and embryo culture media, pose a still unmet challenge regarding the identification of specific biomarkers that will ensure a totally successful outcome. Over the last years, proteomics have been used in almost all relevant biological samples (tissues, fluids, cells) to depict both physiological and pathological states, and have yielded important results, including the significance of posttranslational modifications in sperm and the intense immunological-inflammatory processes that take place during ovulation and implantation, further accentuated in ART. So far, very few of these studies were able to identify uniquely expressed, validated, clinically applicable biomarkers. However, some of these proteins, isolated from non-invasively collected samples, such as embryo culture media, seem to correlate well with embryo quality and fetal aneuploidy and provide hope for a non-invasive characterization of a favorable ART outcome $(105,106)$.

There are still several obstacles to overcome regarding the introduction of proteomic techniques into the everyday clinical practice of a fertility laboratory. It is true that proteomic analysis is a method with quantitative efficiency and high sensitivity. However, the abundance of proteins, such as albumin or immunoglobulins, in biological specimens hinders the recognition of indicative proteins, whose native concentration levels are below picomolar. Currently available MS immunodepletion-based methods have failed to reproducibly capture low-level tissue proteins most likely due to their co-removal by costly, depletion protocols. Therefore, the need arises to develop a method and cost-effective protocol and devices able to detect lowlevel biomarkers in the presence of proteins at multifold order higher concentrations (selectivity and specificity) from small volumes of clinical specimens. Today, 2-D gel electrophoresis allows for the visualization of around 1,000 single spots per gel. The number of proteins identified by that proteomic approach, although significant, is still very low compared to the estimated number of different proteins in any given cell, which is believed to be close to 100,000 or even higher in embryonic cells. Moreover, the minimization of the necessary quantity of "valuable" specimens, such as oocytes or embryo cells, to produce ample proteomic profiles is of outmost importance, as it is clear that our current knowledge on the complete protein expression of the components of mammalian reproduction is still limited. Finally, the validation of derived biomarkers and the clinical interpretation of proteomic results remains the most important challenge regarding the application of proteomics. Undoubtedly, the growing rate of ART worldwide calls for the use of cutting edge research that will provide markers to ensure a successful pregnancy and the birth of a healthy offspring. The comprehensive proteomic profiling of human reproduction and its pathology constitutes a major challenge for the international scientific community and is expected to produce ground-breaking results that will have a major social impact.

\section{References}

1 Shiota $\mathrm{K}$ and Yamada S: Intrauterine environment-genome interaction and children's development (3): Assisted reproductive technologies and developmental disorders. J Toxicol Sci 34: 287-291, 2009.

2 Steptoe PC and Edwards RG: Birth after the reimplantation of a human embryo. Lancet 2(8085): 366-366, 1978. 
3 Palermo G, Joris H, Devroey P and Van Steirteghem AC: Pregnancies after intracytoplasmic injection of single spermatozoon into an oocyte. Lancet 340(8810): 17-18, 1992.

4 Ferraretti P, Goossens V, Kupka M, Bhattacharya S, de Mouzon J, Castilla JA, Erb K, Korsak V and Nyboe Andersen A: Assisted reproductive technology in Europe, 2009: Results generated from European registers by ESHRE. Hum Reprod 28(9): 2318-2331, 2013.

5 Kupka MS, Ferraretti AP, de Mouzon J, Erb K, D’Hooghe T, Castilla JA, Calhaz-Jorge C, De Geyter C, Goossens V; European IVF-Monitoring Consortium, for the European Society of Human Reproduction and Embryology: Assisted reproductive technology in Europe, 2010: results generated from European registers by ESHRE. Hum Reprod 29(10): 2099-2113, 2014.

6 Esteves SC, Zini A, Aziz N, Alvarez JG, Sabanegh ES and Agarwal A: Critical appraisal of World Health Organization's new reference values for human semen characteristics and effect on diagnosis and treatment of subfertile men. Urology 79: 16-22, 2012.

7 Evans J and Salamonsen LA: Inflammation, leukocytes and menstruation. Rev Endocrine Metab Disord 13(4): 277-288, 2012.

8 Papanikolaou EG, Bourgain C, Fatemi H Verpoest W, Polyzos NP, De Brabanter A, Kolibianakis E, Tarlatzis B, Devroey P and Tournaye $\mathrm{H}$ : Endometrial advancement after triggering with recombinant or urinary HCG: a randomized controlled pilot study. Reprod Biomed Online 21: 50-55, 2010.

9 van Vaerenbergh I, Fatemi HM, Blockeel C Van Lommel L, In't Veld P, Schuit F, Kolibianakis EM, Devroey P and Bourgain C: Progesterone rise on $\mathrm{HCG}$ day in GnRH antagonist/rFSH stimulated cycles affects endometrial gene expression. Reprod Biomed Online 22: 263-271, 2011.

10 Basatemur E and Sutcliffe A: Follow-up of children born after ART. Placenta 29(Suppl B): 135-140, 2008.

11 Wen J, Jiang J and Ding C: Birth defects in children conceived by in vitro fertilization and intracytoplasmic sperm injection: a meta-analysis. Fertil Steril 97(6): 1331-1334, 2012.

12 Manipalviratn S, DeCherney A and Segars J: Imprinting disorders and assisted reproductive technology. Fertil Steril 91(2): 305-315, 2009

13 Farquhar C, Rishworth JR, Brown J, Nelen WLDM and Marjoribanks J: Assisted reproductive technology: an overview of Cochrane Reviews. Cochrane Database System Rev 8: CD010537, 2013.

14 Kolialexi A, Mavrou A, Spyrou G and Tsangaris GT: Mass spectrometry-based proteomics in reproductive medicine. Mass Spectr Rev 27: 624-634, 2008.

15 Tsangaris GT: From proteomics research to clinical practice. Expert Review Proteom 6(3): 235-238, 2009.

16 Valledor L and Jorrin J: Back to the basics: Maximizing the information obtained by quantitative two dimensional gel electrophoresis analyses by an appropriate experimental design and statistical analyses. J Proteomics 74(1): 1-18, 2011.

17 Ahrens CH, Brunner E, Qeli E, Basler K and Aebersold R: Generating and navigating proteome maps using mass spectrometry. Nat Rev Mol Cell Biol 11(11): 789-801, 2010.

18 Liebler DC: Introduction to Proteomics: Tools for the New Biology (Humana Press, Inc., Totowa, NJ, 2002).

19 O'Farrell PH: The pre-omics era: the early days of twodimensional gels. Proteomics 8: 4842-4852, 2008.
20 Dowsey AW, Dunn MJ and Yang GZ: The role of bioinformatics in two-dimensional gel electrophoresis. Proteomics 3(8): 1567-1596, 2003.

21 Schirmer EC, Yates 3rd JR and Gerace L: MudPIT: A powerful proteomics tool for discovery. Discov Med 3(18): 38-39, 2003.

22 Perkins DN, Pappin DJ, Creasy DM and Cottrell JS: Probability-based protein identification by searching sequence databases using mass spectrometry data. Electrophoresis 20(18): 3551-3567, 1999.

23 Yates 3rd JR, Eng JK, McCormack AL and Schieltz D: Method to correlate tandem mass spectra of modified peptides to amino acid sequences in the protein database. Anal Chem 67(8): 14261436,1995

24 Craig R and Beavis RC: TANDEM: matching proteins with tandem mass spectra. Bioinformatics 20(9): 1466-1467, 2004.

25 Gygi SP, Rist B, Gerber SA, Turecek F, Gelb MH and Aebersold R: Quantitative analysis of complex protein mixtures using isotope-coded affinity tags. Nat Biotechnol 17(10): 994999, 1999.

26 Thompson A, Schafer J, Kuhn K Kienle S, Schwarz J, Schmidt G, Neumann T, Johnstone R, Mohammed AK and Hamon C: Tandem mass tags: a novel quantification strategy for comparative analysis of complex protein mixtures by MS/MS. Anal Chem 75(8): 1895-1904, 2003.

27 Ong SE, Blagoev B, Kratchmarova I, Kristensen DB, Steen H, Pandey A and Mann M: Stable isotope labeling by amino acids in cell culture, SILAC, as a simple and accurate approach to expression proteomics. Mol Cell Proteomics 1(5): 376-386, 2002.

28 Angel TE, Aryal UK, Hengel SM, Baker ES, Kelly RT, Robinson EW and Smith RD: Mass spectrometry-based proteomics: existing capabilities and future directions. Chem Soc Rev 41(10): 3912-3928, 2012.

29 Apweiler R, Aslanidis C, Deufel T Gerstner A, Hansen J, Hochstrasser D, Kellner R, Kubicek M, Lottspeich F, Maser E, Mewes HW, Meyer HE, Müllner S, Mutter W, Neumaier M, Nollau P, Nothwang HG, Ponten F, Radbruch A, Reinert K, Rothe G, Stockinger H, Tarnok A, Taussig MJ, Thiel A, Thiery J, Ueffing $M$, Valet $G$, Vandekerckhove $J$, Verhuven $W$, Wagener C, Wagner O and Schmitz G: Approaching clinical proteomics: current state and future fields of application in fluid proteomics. Clin Chem Lab Med 47(6): 724-744, 2009.

30 Barbosa EB, Vidotto A, Polachini GM, Henrique T, Marqui AB and Tajara EH: Proteomics: methodologies and applications to the study of human diseases. Rev Assoc Med Bras 58(3): 366-375, 2012.

$31 \mathrm{Hu} \mathrm{S}$, Loo JA and Wong DT: Human body fluid proteome analysis. Proteomics 6(23): 6326-6353, 2006.

32 Sharlip ID, Jarow JP, Belker AM, Lipshultz LI, Sigman M, Thomas AJ, Schlegel PN, Howards SS, Nehra A, Damewood MD, Overstreet JW and Sadovsky R: Best practice policies for male infertility. Fertil Steril 77: 873-882, 2002.

33 Turek PJ: Practical approaches to the diagnosis and management of male infertility. Nat Clin Pract Urol 2: 226-238, 2005.

34 Guo X, Zhang P, Huo R, Zhou Z and Sha J: Analysis of the human testis proteome by mass spectrometry and bioinformatics. Proteomics Clin Appl 2: 1651-1657, 2008.

35 Li J, Liu F, Liu X Liu J, Zhu P, Wan F, Jin S, Wang W, Li N, Liu $J$ and Wang $\mathrm{H}$ : Mapping of the human testicular proteome and its relationship with that of the epididymis and spermatozoa. Mol Cell Proteomics 10(3): M110.004630M004110.004630, 2011 
36 Guo X, Zhao C, Wang F Zhu Y, Cui Y, Zhou Z, Huo R and Sha $\mathrm{J}$ : Investigation of human testis protein heterogeneity using 2dimensional electrophoresis. J Androl 31(4): 419-429, 2010.

37 Macleod G and Varmuza S: The application of proteomic approaches to the study of mammalian spermatogenesis and sperm function. FEBS J 280(22): 5635-5651, 2013.

38 Li J, Guo W, Li F He J, Yu Q, Wu X, Li J and Mao X: HnRNPL as a key factor in spermatogenesis: Lesson from functional proteomic studies of azoospermia patients with sertoli cell only syndrome. J Proteomics 75(10): 2879-2891, 2012.

39 du Plessis SS, Kashou AH, Benjamin DJ, Yadav SP and Agarwal A: Proteomics: a subcellular look at spermatozoa. Rep Biol Endocrinol 9: 36, 2011.

40 Belleannee C, Belghazi M, Labas V Teixeira-Gomes AP, Gatti JL, Dacheux JL and Dacheux F: Purification and identification of sperm surface proteins and changes during epididymal maturation. Proteomics 11: 1952-1964, 2011.

41 Gu B, Zhang J, Wu Y Zhang X, Tan Z, Lin Y, Huang X, Chen $\mathrm{L}$, Yao $\mathrm{K}$ and Zhang M: Proteomic analyses reveal common promiscuous patterns of cell surface proteins on human embryonic stem cells and sperms. PloS One 6: e19386, 2011.

42 Nixon B, Mitchell LA, Anderson AL, McLaughlin EA, O'bryan MK and Aitken RJ: Proteomic and functional analysis of human sperm detergent resistant membranes. J Cell Physiol 226: 26512665, 2011.

43 Amaral A, Castillo J, Estanyol JM, Ballescà JL, RamalhoSantos J and Oliva R: Human sperm tail proteome suggests new endogenous metabolic pathways. Mol Cell Proteomics 12: 330342, 2013.

44 Baker MA, Naumovski N, Hetherington L, Weinberg A, Velkov $\mathrm{T}$ and Aitken RJ: Head and flagella subcompartmental proteomic analysis of human spermatozoa. Proteomics 13: 6174, 2013

45 de Mateo S, Castillo J, Estanyol JM, Ballescà JL and Oliva R: Proteomic characterization of the human sperm nucleus. Proteomics 11(13): 2714-2726, 2011.

46 Amaral A, Castillo J, Ramalho-Santos J and Oliva R: The combined human sperm proteome: cellular pathways and implications for basic and clinical science. Hum Reprod Update 20(1): 40-62, 2014.

47 Castillo J, Amaral A, Azpiazu R Vavouri T, Estanyol JM, Ballescà JL and Oliva R: Genomic and proteomic dissection and characterization of the human sperm chromatin. Mol Hum Reprod 20(11): 1041-1053, 2014.

48 Porambo JR, Salicioni AM, Visconti PE and Platt MD: Sperm phosphoproteomics: historical perspectives and current methodologies. Exp Rev Proteomics 9: 533-548, 2012.

49 Shetty J, Diekman AB, Jayes FC Sherman NE, NaabyHansen S, Flickinger CJ and Herr JC: Differential extraction and enrichment of human sperm surface proteins in a proteome: identification of immunocontraceptive candidates. Electrophoresis 22: 3053-3066, 2001.

50 Ficarro S, Chertihin O, Westbrook VA White F, Jayes F, Kalab P, Marto JA, Shabanowitz J, Herr JC, Hunt DF and Visconti PE: Phosphoproteome analysis of capacitated human sperm. Evidence of tyrosine phosphorylation of a kinase-anchoring protein 3 and valosin-containing protein/p97 during capacitation. J Biol Chem 278: 11579-11589, 2003.

51 Wang J, Qi L, Huang S Zhou T, Guo Y, Wang G, Guo X, Zhou $\mathrm{Z}$ and Sha J: Quantitative phosphoproteomics analysis reveals a key role of insulin growth factor 1 receptor (IGF1R) tyrosine kinase in human sperm capacitation. Mol Cell Proteomics 14(4): 1104-1112, 2015.

52 Lefièvre L, Chen Y, Conner SJ, Scott JL, Publicover SJ, Ford WC, Barratt CL: Human spermatozoa contain multiple targets for protein S-nitrosylation: an alternative mechanism of the modulation of sperm function by nitric oxide? Proteomics 7(17): 3066-3084, 2007.

53 Pixton KL, Deeks ED, Flesch FM Moseley FL, Björndahl L, Ashton PR, Barratt CL and Brewis IA: Sperm proteome mapping of a patient who experienced failed fertilization at IVF reveals altered expression of at least 20 proteins compared with fertile donors: case report. Hum Reprod 19(6): 1438-1447, 2004.

54 de Mateo S, Martínez-Heredia J, Estanyol JM Domínguez-Fandos $\mathrm{D}$, Vidal-Taboada JM, Ballescà JL and Oliva R: Marked correlations in protein expression identified by proteomic analysis of human spermatozoa. Proteomics 7(23): 4264-4277, 2007.

55 Martínez-Heredia J, de Mateo S, Vidal-Taboada JM, Ballescà $\mathrm{JL}$ and Oliva R: Identification of proteomic differences in asthenozoospermic sperm samples. Hum Reprod 23: 783-791, 2008.

56 Redgrove KA, Nixon B, Baker MA Hetherington L, Baker G, Liu DY and Aitken RJ: The molecular chaperone HSPA2 plays a key role in regulating the expression of sperm surface receptors that mediate sperm-egg recognition. PloS One 7: e50851, 2012.

57 Zhao C, Huo R, Wang F-Q, Lin M, Zhou Z-M and Sha J-H: Identification of several proteins involved in regulation of sperm motility by proteomic analysis. Fertil Steril 87(2): 436438, 2007.

58 Shen S, Wang J, Liang J and He D: Comparative proteomic study between human normal motility sperm and idiopathic asthenozoospermia. World J Urol 31(6): 1395-1401, 2013.

59 Siva AB, Kameshwari DB, Singh V Pavani K, Sundaram CS, Rangaraj N, Deenadayal M and Shivaji S: Proteomics-based study on asthenozoospermia: differential expression of proteasome alpha complex. Mol Hum Reprod 16: 452-462, 2010.

60 Thacker S, Yadav SP, Sharma RK, Ashou A, Willard B, Zhang $\mathrm{D}$ and Agarwal A: Evaluation of sperm proteins in infertile men: a proteomic approach. Fertil Steril 95(8): 2745-2748, 2011.

61 Xu W, Hu H, Wang Z Chen X, Yang F, Zhu Z, Fang P, Dai J, Wang L, Shi H, Li Z and Qiao Z: Proteomic characteristics of spermatozoa in normozoospermic patients with infertility. J Proteomics 75(17): 5426-5436, 2012.

62. Frapsauce C, Pionneau C, Bouley J, de Larouzière V, Berthaut I, Ravel C, Antoine JM, Soubrier and Mandelbaum J: Unexpected in vitro fertilization failure in patients with normal sperm: a proteomic analysis. Gynecol Obstet Fertil 37(10): 796$802,2009$.

63 Zhu Y, Wu Y, Jin K, Lu H, Liu F, Guo Y, Yan F, Shi W, Liu Y, Cao X, Hu H, Zhu H, Guo X, Sha J, Li Z and Zhou Z: Differential proteomic profiling in human spermatozoa that did or did not result in pregnancy via IVF and AID. Proteomics Clin Appl 7(11-12): 850-858, 2013.

64 McReynolds S, Dzieciatkowska M, Stevens J, Hansen KC, Schoolcraft WB and Katz-Jaffe MG: Toward the identification of a subset of unexplained infertility: a sperm proteomic approach. Fertil Steril 102(3): 692-699, 2014. 
65 Parte PP, Rao P, Redij S, Lobo V, D’Souza SJ, Gajbhiye R and Kulkarni V: Sperm phosphoproteome profiling by ultra performance liquid chromatography followed by data independent analysis (LC-MS(E)) reveals altered proteomic signatures in asthenozoospermia. J Proteomics 75(18): 5861-5871, 2012.

66 Vigodner M, Shrivastava V, Gutstein LE, Schneider J, Nieves E, Goldstein M, Feliciano M, Callaway M. Localization and identification of sumoylated proteins in human sperm: excessive sumoylation is a marker of defective spermatozoa. Hum Reprod 28: 210-223, 2013.

67 Duncan MW and Thompson HS: Proteomics of semen and its constituents. Proteomics Clin Applic 1: 861-875, 2007.

68 Fung KYC, Glode LM, Green S and Duncan MW: A comprehensive characterization of the peptide and protein constituents of human seminal fluid. Prostate 61: 171-181, 2004.

69 Pilch B and Mann M: Large-scale and high-confidence proteomic analysis of human seminal plasma. Gen Biol 7(5): R40-R40, 2006.

70 Milardi D, Grande G, Vincenzoni F, Messana I, Pontecorvi A, De Marinis L, Castagnola M, Marana R: Proteomic approach in the identification of fertility pattern in seminal plasma of fertile men. Fertil Steril 97: 67-73:e61, 2012.

71 Starita-Geribaldi M, Poggioli S, Zucchini M, Garin J, Chevallier D, Fenichel P, Pointis G: Mapping of seminal plasma proteins by two-dimensional gel electrophoresis in men with normal and impaired spermatogenesis. Mol Hum Reprod 7: 715-722, 2001.

72 Yamakawa K, Yoshida K, Nishikawa H, Kato T and Iwamoto $\mathrm{T}$ : Comparative analysis of interindividual variations in the seminal plasma proteome of fertile men with identification of potential markers for azoospermia in infertile patients. J Androl 28(6): 858-865, 2007

73 Batruch I, Lecker I, Kagedan D, Smith CR, Mullen BJ, Grober E, Lo KC, Diamandis EP and Jarvi KA: Proteomic analysis of seminal plasma from normal volunteers and post-vasectomy patients identifies over 2000 proteins and candidate biomarkers of the urogenital system. J Proteome Res 10: 941-953, 2011.

74 Batruch I, Smith CR, Mullen BJ, Grober E, Lo KC, Diamandis EP and Jarvi KA: Analysis of seminal plasma from patients with non-obstructive azoospermia and identification of candidate biomarkers of male infertility. J Proteome Res 11(3): 1503-1511, 2012.

75 Drabovich AP, Dimitromanolakis A, Saraon P, Soosaipillai A, Batruch I, Mullen B, Jarvi K and Diamandis EP: Differential diagnosis of azoospermia with proteomic biomarkers ECM1 and TEX101 quantified in seminal plasma. Sci Transl Med 5: 212ra160, 2013

76 Wang J, Wang J, Zhang H-R, Shi HJ, Ma D, Zhao HX, Lin B and $\mathrm{Li} \mathrm{RS}$ : Proteomic analysis of seminal plasma from asthenozoospermia patients reveals proteins that affect oxidative stress responses and semen quality. Asian J Androl 11(4): 484-491, 2009.

77 Kumar V, Hassan MI, Tomar AK, Kashav T, Nautiyal J, Singh S, Singh TP and Yadav S: Proteomic analysis of heparinbinding proteins from human seminal plasma: a step towards identification of molecular markers of male fertility. J Biosci 34: 899-908, 2009.

78 Davalieva K, Kiprijanovska S, Noveski P, Plaseski T, Kocevska B, Broussard C and Plaseska-Karanfilska D: Proteomic analysis of seminal plasma in men with different spermatogenic impairment. Andrologia 44(4): 256-264, 2012.
79 Sharma R, Agarwal A, Mohanty G, Jesudasan R, Gopalan B, Willard B, Yadav SP and Sabanegh E: Functional proteomic analysis of seminal plasma proteins in men with various semen parameters. Reprod Biol Endocrinol 11: 38-38, 2013.

80 Sharma R, Agarwal A, Mohanty G, Hamada AJ, Gopalan B, Willard B, Yadav S and du Plessis S: Proteomic analysis of human spermatozoa proteins with oxidative stress. Reprod Biol Endocrinol 11: 48-48, 2013.

81 Herwig R, Knoll C, Planyavsky M, Pourbiabany A, Greilberger $\mathrm{J}$ and Bennett KL: Proteomic analysis of seminal plasma from infertile patients with oligoasthenoteratozoospermia due to oxidative stress and comparison with fertile volunteers. Fertil Steril 100: 355-366.e352, 2013.

82 Intasqui P, Camargo M, Antoniassi MP, Cedenho AP, Carvalho VM, Cardozo KH, Zylbersztejn DS and Bertolla RP: Association between the seminal plasma proteome and sperm functional traits. Fertil Steril 105(3): 617-628, 2016.

83 Revelli A, Delle Piane L, Casano S, Molinari E, Massobrio M and Rinaudo P: Follicular fluid content and oocyte quality: from single biochemical markers to metabolomics. Reprod Biol Endocrinol 7: 40, 2009.

84 Schweigert FJ, Gericke B, Wolfram W, Kaisers U and Dudenhausen JW: Peptide and protein profiles in serum and follicular fluid of women undergoing IVF. Hum Reprod 21(11): 2960-2968, 2006.

85 Angelucci S, Ciavardelli D, Di Giuseppe F, Eleuterio E, Sulpizio M, Tiboni GM, Giampietro F, Palumbo P and Di Ilio C: Proteome analysis of human follicular fluid. Biochim Biophys Acta 1764(11): 1775-1785, 2006.

86 Twigt J, Steegers-Theunissen RP, Bezstarosti K and Demmers JAA: Proteomic analysis of the microenvironment of developing oocytes. Proteomics 12(9): 1463-1471, 2012.

87 Jarkovska K, Kupcova Skalnikova H, Halada P, Hrabakova R, Moos J, Rezabek K, Gadher SJ and Kovarova H: Development of ovarian hyperstimulation syndrome: interrogation of key proteins and biological processes in human follicular fluid of women undergoing in vitro fertilization. Mol Hum Reprod 17(11): 679-692, 2011.

88 Spanel-Borowski K: Ovulation as danger signaling event of innate immunity. Mol Cell Endocrinol 333: 1-7, 2011

89 Bianchi L, Gagliardi A, Campanella G, Landi C, Capaldo A, Carleo A, Armini A, De Leo V, Piomboni P, Focarelli R and Bini L: A methodological and functional proteomic approach of human follicular fluid en route for oocyte quality evaluation. J Proteomics 90: 61-76, 2013.

90 Wu YT, Wu Y, Zhang JY, Hou NN, Liu AX, Pan JX, Lu JY, Sheng JZ and Huang HF: Preliminary proteomic analysis on the alterations in follicular fluid proteins from women undergoing natural cycles or controlled ovarian hyperstimulation. J Assist Reprod Genet 32(3): 417-427, 2015.

91 Jarkovska K, Martinkova J, Liskova L, Halada P, Moos J, Rezabek K, Gadher SJ, Kovarova H: Proteome mining of human follicular fluid reveals a crucial role of complement cascade and key biological pathways in women undergoing in vitro fertilization. J Proteome Res 9(3): 1289-1301, 2010.

92 Estes SJ, Ye B, Qiu W, Cramer D, Hornstein MD and Missmer SA: A proteomic analysis of IVF follicular fluid in women $<$ or=32 years old. Fertil Steril 92(5): 1569-1578, 2009.

93 Ambekar AS, Nirujogi RS, Srikanth SM, Chavan S, Kelkar DS, Hinduja I, Zaveri K, Prasad TS, Harsha HC, Pandey A, 
Mukherjee S: Proteomic analysis of human follicular fluid: A new perspective towards understanding folliculogenesis. J Proteomics 87: 68-77, 2013.

94 Hashemitabar M, Bahmanzadeh M, Mostafaie A, Orazizadeh M, Farimani $M$ and Nikbakht R: A proteomic analysis of human follicular fluid: comparison between younger and older women with normal FSH levels. Int J Mol Sci 15(10): 1751817540, 2014.

95 Larsen WJ, Wert SE and Brunner GD: A dramatic loss of cumulus cell gap junctions is correlated with germinal vesicle breakdown in rat oocytes. Dev Biol 113: 517-521, 1986.

96 Sato C, Shimada M, Mori T, Kumasako Y, Otsu E, Watanabe H and Utsunomiya T: Assessment of human oocyte developmental competence by cumulus cell morphology and circulating hormone profile. Reprod BioMed Online 14(1): 49-56, 2007.

97 Hamamah S, Matha V, Berthenet C, Anahory T, Loup V, Dechaud H, Hedon B, Fernandez A and Lamb N: Comparative protein expression profiling in human cumulus cells in relation to oocyte fertilization and ovarian stimulation protocol. Reprod Biomed Online 13(6): 807-814, 2006.

98 Braga DPAF, Setti AS, Lo Turco EG, Cordeiro FB, Cabral EC, Cortezzi SS, Ono E, Figueira RC, Eberlin MN and Borges E $\mathrm{Jr}$.: Protein expression in human cumulus cells as an indicator of blastocyst formation and pregnancy success. J Assist Reprod Genet 33(12): 1571-1583, 2016.

99 Aydiner F, Yetkin CE and Seli E: Perspectives on emerging biomarkers for non-invasive assessment of embryo viability in assisted reproduction. Cur Mol Med 10: 206-215, 2010.

100 Scott RT and Treff NR: Assessing the reproductive competence of individual embryos: a proposal for the validation of new "omics" technologies. Ferti Steril 94(3): 791-794, 2010.

101 Brison DR, Houghton FD, Falconer D, Roberts SA, Hawkhead J, Humpherson PG, Lieberman BA and Leese HJ: Identification of viable embryos in IVF by non-invasive measurement of amino acid turnover. Hum Reprod 19: 2319-2324, 2004.

102 Katz-Jaffe MG, Schoolcraft WB and Gardner DK: Analysis of protein expression (secretome) by human and mouse preimplantation embryos. Fertil Steril 86(3): 678-685, 2006.

103 Katz-Jaffe MG, Gardner DK and Schoolcraft WB: Proteomic analysis of individual human embryos to identify novel biomarkers of development and viability. Fertil Steril 85: 101107, 2006.

104 Cortezzi SS, Garcia JS, Ferreira CR, Braga DP, Figueira RC, Iaconelli A Jr., Souza GH, Borges E Jr. and Eberlin MN: Secretome of the preimplantation human embryo by bottom-up label-free proteomics. Anal Bioanal Chem 401(4): 1331-1339, 2011.

105 Mains LM, Christenson L, Yang B, Sparks AE, Mathur S and Van Voorhis BJ: Identification of apolipoprotein A1 in the human embryonic secretome. Fertil Steril 96(2): 422-427.e422, 2011.

106 McReynolds S, Vanderlinden L, Stevens J, Hansen K, Schoolcraft WB and Katz-Jaffe MG: Lipocalin-1: a potential marker for noninvasive aneuploidy screening. Fertil Steril 95(8): 2631-2633, 2011.

107 Dyrlund TF, Kirkegaard K, Poulsen ET, Sanggaard KW, Hindkjær JJ, Kjems J, Enghild JJ and Ingerslev HJ: Unconditioned commercial embryo culture media contain a large variety of non-declared proteins: a comprehensive proteomics analysis. Hum Reprod 29(11): 2421-2430, 2014.
108 Poli M, Ori A, Child T, Jaroudi S, Spath K, Beck M and Wells $\mathrm{D}$ : Characterization and quantification of proteins secreted by single human embryos prior to implantation. EMBO Mol Med 7(11): 1465-1479, 2015.

109 Salamonsen LA, Edgell T, Rombauts LJ, Stephens AN, Robertson DM, Rainczuk A, Nie G and Hannan NJ: Proteomics of the human endometrium and uterine fluid: a pathway to biomarker discovery. Fertil Steril 99(4): 1086-1092, 2013.

110 DeSouza L, Diehl G, Yang EC, Guo J, Rodrigues MJ, Romaschin AD, Colgan TJ and Siu KW: Proteomic analysis of the proliferative and secretory phases of the human endometrium: protein identification and differential protein expression. Proteomics 5: 270-281, 2005.

111 Chen JIC, Hannan NJ, Mak Y, Nicholls PK, Zhang J, Rainczuk A, Stanton PG, Robertson DM, Salamonsen LA and Stephens AN: Proteomic characterization of midproliferative and midsecretory human endometrium. J Proteome Res 8: 20322044, 2009.

112 Hood BL, Liu B, Alkhas A Shoji Y, Challa R, Wang G, Ferguson S, Oliver J, Mitchell D, Bateman NW, Zahn CM, Hamilton CA, Payson M, Lessey B, Fazleabas AT, Maxwell GL, Conrads TP and Risinger JI: Proteomics of the human endometrial glandular epithelium and stroma from the proliferative and secretory phases of the menstrual cycle. Biol Reprod 92(4): 106-106, 2015.

113 Domínguez F, Garrido-Gómez T, López JA, Camafeita E, Quiñonero A, Pellicer A and Simón C: Proteomic analysis of the human receptive versus non-receptive endometrium using differential in-gel electrophoresis and MALDI-MS unveils stathmin 1 and annexin A2 as differentially regulated. Hum Reprod 24: 2607-2617, 2009.

114 Haouzi D, Dechaud H, Assou S, De Vos J and Hamamah S: Insights into human endometrial receptivity from transcriptomic and proteomic data. Reprod Biomed Online 24(1): 23-34, 2012.

115 Parmar T, Gadkar-Sable S, Savardekar L, Katkam R, Dharma S, Meherji P, Puri CP, Sachdeva G: Protein profiling of human endometrial tissues in the midsecretory and proliferative phases of the menstrual cycle. Fertil Steril 92: 1091-1103, 2009.

116 Garrido-Gomez T, Quinonero A, Antunez O, Díaz-Gimeno P, Bellver J, Simón C and Domínguez F: Deciphering the proteomic signature of human endometrial receptivity. Hum Reprod 29(9): 1957-1967, 2014.

117 Meng Y, Guo Y, Qian Y, Guo X, Gao L, Sha J, Cui Y, Chian $\mathrm{RC}$ and Liu J: Effects of GnRH antagonist on endometrial protein profiles in the window of implantation. Proteomics 14(20): 2350-2359, 2014.

118 Edgell Ta, Rombauts LJF and Salamonsen LA: Assessing receptivity in the endometrium: the need for a rapid, noninvasive test. Reprod Biomed Online 27(5): 486-496, 2013.

119 Casado-Vela J, Rodriguez-Suarez E, Iloro I, Ametzazurra A, Alkorta N, García-Velasco JA, Matorras R, Prieto B, González S, Nagore D, Simón L and Elortza F: Comprehensive proteomic analysis of human endometrial fluid aspirate. J Proteome Res 8: 4622-4632, 2009.

120 Hannan NJ, Stephens AN, Rainczuk A, Hincks C, Rombauts LJ and Salamonsen LA: 2D-DiGE analysis of the human endometrial secretome reveals differences between receptive and non-receptive states in fertile and infertile women. J Proteome Res 9(12): 6256-6264, 2010. 
121 Scotchie JG, Fritz MA, Mocanu M, Lessey BA and Young SL: Proteomic analysis of the luteal endometrial secretome. Reproductive Sci 16(9): 883-893, 2009.

122 Bhutada S, Basak T, Savardekar L, Katkam RR, Jadhav G, Metkari SM, Chaudhari UK, Kumari D, Kholkute SD, Sengupta $\mathrm{S}$ and Sachdeva G: High mobility group box 1 (HMGB1) protein in human uterine fluid and its relevance in implantation. Hum Reprod 29(4): 763-780, 2014.

123 Bhagwat SR, Redij T, Phalnikar K, Nayak S, Iyer S, Gadkar S, Chaudhari U, Kholkute SD and Sachdeva G: Cell surfactomes of two endometrial epithelial cell lines that differ in their adhesiveness to embryonic cells. Mol Reprod Dev 81(4): 326340, 2014.

124 Zhang Y, Zhang YL, Feng C, Wu YT, Liu AX, Sheng JZ, Cai J and Huang HF: Comparative proteomic analysis of human placenta derived from assisted reproductive technology. Proteomics 8(20): 4344-4356, 2008.

125 Galazis N, Afxentiou T, Xenophontos M, Diamanti-Kandarakis E and Atiomo W: Proteomic biomarkers of type 2 diabetes mellitus risk in women with polycystic ovary syndrome. Eur J Endocrinol 168: R33-43, 2013.

126 Goldenberg RL, Iams JD, Mercer BM, Meis PJ, Moawad A, Das A, Miodovnik M, Vandorsten PJ, Caritis SN, Thurnau G and Dombrowski MP: The Preterm Prediction Study: toward a multiple-marker test for spontaneous preterm birth. Am J Obstet Gynecol 185: 643-651, 2001.

127 Esplin MS, Merrell K, Goldenberg R, Lai Y, Iams JD, Mercer B, Spong CY, Miodovnik M, Simhan HN, van Dorsten P and Dombrowski M: Proteomic identification of serum peptides predicting subsequent spontaneous preterm birth. Am J Obstet Gynecol 204(5): 391.e391-398, 2011.

128 Butt RH, Lee MW, Pirshahid SA, Backlund PS, Wood S and Coorssen JR: An initial proteomic analysis of human preterm labor: placental membranes. J Proteome Res 5(11): 3161-3172, 2006.

129 Ni X, Li X, Guo Y, Zhou T, Guo X, Zhao C, Lin M, Zhou Z, Shen R, Guo X, Ling X and Huo R: Quantitative proteomics analysis of altered protein expression in the placental villous tissue of early pregnancy loss using isobaric tandem mass tags. BioMed Res Int 2014: 647143, 2014.

130 Katalinic A, Rösch C and Ludwig M: Pregnancy course and outcome after intracytoplasmic sperm injection: a controlled, prospective cohort study. Fertil Steril 81(6): 1604-1616, 2004.

131 Ferraretti AP, Goossens V, de Mouzon J, Bhattacharya S, Castilla JA, Korsak V, Kupka M, Nygren KG and Nyboe Andersen A: Assisted reproductive technology in Europe, 2008: results generated from European registers by ESHRE. Hum Reprod 27(9): 2571-2584, 2012.

132 Sun CJ, Yan LY, Wang W, Yu S, Wang X and Zhang WY: Proteomic analysis of the alteration of protein expression in the placenta of Down syndrome. Chin Med J 124(22): 3738-3745, 2011.

133 Wang TH, Chang YL, Peng HH, Wang ST, Lu HW, Teng SH, Chang SD and Wang HS: Rapid detection of fetal aneuploidy using proteomics approaches on amniotic fluid supernatant. Prenat Diagn 25(7): 559-566, 2005.

134 Tsangaris GT, Karamessinis P, Kolialexi A, Garbis SD, Antsaklis A, Mavrou A and Fountoulakis M: Proteomic analysis of amniotic fluid in pregnancies with Down syndrome. Proteomics 6(15): 4410-4419, 2006.
135 Kolialexi A, Tsangaris GT, Papantoniou N, Anagnostopoulos AK, Vougas K, Bagiokos V, Antsaklis A and Mavrou A: Application of proteomics for the identification of differentially expressed protein markers for Down syndrome in maternal plasma. Prenatal diagnosis 28: 691-698, 2008.

136 Nagalla SR, Canick JA, Jacob T, Schneider KA, Reddy AP, Thomas A, Dasari S, Lu X, Lapidus JA, Lambert-Messerlian GM, Gravett MG, Roberts CT Jr., Luthy D, Malone FD and D'Alton ME: Proteomic analysis of maternal serum in down syndrome: identification of novel protein biomarkers. J Proteome Res 6(4): 1245-1257, 2007.

137 Mavrou A, Anagnostopoulos AK, Kolialexi A, Vougas K, Papantoniou N, Antsaklis A, Fountoulakis M and Tsangaris GT: Proteomic analysis of amniotic fluid in pregnancies with Turner syndrome fetuses. J Proteome Res 7: 1862-1866, 2008.

138 Kolialexi A, Anagnostopoulos AK, Papantoniou N Vougas K, Antsaklis A, Fountoulakis M, Mavrou A and Tsangaris GT: Potential biomarkers for Turner in maternal plasma: possibility for noninvasive prenatal diagnosis. J Proteome Res 9: 5164$5170,2010$.

139 Sui W, Zhang R, Chen J, He H, Cui Z, Ou M, Li W, Qi S, Wen $\mathrm{J}$, Lin X and Dai Y: Quantitative proteomic analysis of Down syndrome in the umbilical cord blood using iTRAQ. Mol Med Rep 11(2): 1391-1399, 2015.

140 Karamessinis PM, Malamitsi-Puchner A, Boutsikou T, Makridakis M, Vougas K, Fountoulakis M, Vlahou A and Chrousos G: Marked defects in the expression and glycosylation of alpha2-HS glycoprotein/fetuin-A in plasma from neonates with intrauterine growth restriction: proteomics screening and potential clinical implications. Mol Cell Proteomics 7(3): 591-599, 2008.

141 Cecconi D, Lonardoni F, Favretto D, Cosmi E, Tucci M, Visentin S, Cecchetto G, Fais P, Viel G and Ferrara SD: Changes in amniotic fluid and umbilical cord serum proteomic profiles of foetuses with intrauterine growth retardation. Electrophoresis 32(24): 3630-3637, 2011.

142 Miao Z, Chen M, Wu H, Ding H and Shi Z: Comparative proteomic profile of the human placenta in normal and fetal growth restriction subjects. Cell Physiol Biochem 34(5): 17011710, 2014.

143 Belva F, Painter R, Bonduelle M, Roelants M, Devroey P and De Schepper J: Are ICSI adolescents at risk for increased adiposity? Hum Reprod 27(1): 257-264, 2012.

144 Ceelen M, van Weissenbruch MM, Vermeiden JP, van Leeuwen FE and Delemarre-van de Waal HA: Cardiometabolic differences in children born after in vitro fertilization: follow-up study. J Clin Endocrinol Metab 93(5): 1682-1688, 2008.

145 Gkourogianni A, Kosteria I, Telonis AG, Margeli A, Mantzou E, Konsta M, Loutradis D, Mastorakos G, Papassotiriou I, Klapa MI, Kanaka-Gantenbein C and Chrousos GP: Plasma Metabolomic Profiling Suggests Early Indications for Predisposition to Latent Insulin Resistance in Children Conceived by ICSI. PloS One 9: e94001, 2014.

146 Sakka SD, Loutradis D, Kanaka-Gantenbein C, Margeli A, Papastamataki M, Papassotiriou I and Chrousos GP: Absence of insulin resistance and low-grade inflammation despite early metabolic syndrome manifestations in children born after in vitro fertilization. Fertil Steril 94: 1693-1699, 2010. 
147 Seggers J, Haadsma ML, La Bastide-Van Gemert S, Heineman MJ, Middelburg KJ, Roseboom TJ, Schendelaar P, Van den Heuvel ER and Hadders-Algra M: Is ovarian hyperstimulation associated with higher blood pressure in 4-year-old IVF offspring? Part I: multivariable regression analysis. Human Reprod 29: 502-509, 2014.

148 Grace KS and Sinclair KD: Assisted reproductive technology, epigenetics, and long-term health: a developmental time bomb still ticking. Semin Reprod Med 27(5): 409-416, 2009.

149 Barker DJ: Fetal origins of cardiovascular disease. Ann Med 31: 3-6, 1999.

150 Gluckman PD, Cutfield W, Hofman P and Hanson MA: The fetal, neonatal, and infant environments-the long-term consequences for disease risk. Early Hum Dev 81(1): 51-59, 2005.

151 Ceelen M, van Weissenbruch MM, Roos JC, Vermeiden JP, van Leeuwen FE and Delemarre-van de Waal HA: Body composition in children and adolescents born after in vitro fertilization or spontaneous conception. J Clin Endocrinol Metab 92(9): 3417-3423, 2007.

152 Santos MA, Kuijk EW and Macklon NS: The impact of ovarian stimulation for IVF on the developing embryo. Reproduction 139(1): 23-34, 2010.

153 Khosla S, Dean W, Brown D, Reik W and Feil R: Culture of preimplantation mouse embryos affects fetal development and the expression of imprinted genes. Biol Reprod 64(3): 918-926, 2001.

154 Allen C, Reardon W and States U: Assisted reproduction technology and defects of genomic imprinting. Bjog 112(12): 1589-1594, 2005.
155 Laprise SL: Implications of epigenetics and genomic imprinting in assisted reproductive technologies. Mol Reprod Dev 76(11): 1006-1018, 2009.

156 Chrousos GP: The role of stress and the hypothalamic-pituitaryadrenal axis in the pathogenesis of the metabolic syndrome: neuro-endocrine and target tissue-related causes. Int J Obes Relat Metab Disord 24: S50-55, 2000.

157 Kanaka-Gantenbein C, Mastorakos G and Chrousos GP: Endocrine-related causes and consequences of intrauterine growth retardation. Ann NY Acad Sci 997: 150-157, 2003.

158 Di Girolamo F, Del Chierico F, Caenaro G, Lante I, Muraca M, Putignani L. Human serum proteome analysis: new source of markers in metabolic disorders. Biomark Med 6(6): 759-773, 2012.

159 Galazis N, Afxentiou T, Xenophontos M, Diamanti-Kandarakis $\mathrm{E}$ and Atiomo W: Proteomic biomarkers of type 2 diabetes mellitus risk in women with polycystic ovary syndrome. Eur $\mathrm{J}$ Endocrinol 168(2): R33-43, 2013.
Received February 19, 2017

Revised March 1, 2017

Accepted March 2, 2017 